\title{
Interesses e dificuldades dos pais na alfabetização dos filhos
}

\author{
Eliane Porto Di Nucci \\ Universidade São Francisco
}

\begin{abstract}
Resumo
Realizar um levantamento de dados referentes aos interesses e às dificuldades dos pais em relação à participação na alfabetização de seus filhos foi o principal objetivo deste estudo. Foram sujeitos desta pesquisa 25 mães de crianças em pré-escola e $1^{\text {a }}$ série de uma escola particular. Foi utilizado um questionário com duas perguntas sobre os interesses e as dificuldades dos sujeitos e sobre a disponibilidade de tempo neste contexto. Os resultados mostraram que os sujeitos parecem estar dispostos a participar mais efetivamente desse processo em casa e em parceria com a escola. Os interesses parecem estar voltados à evolução da escrita na criança e aos métodos de alfabetização. As dificuldades apareceram em relação às condutas diante da aprendizagem da criança.
\end{abstract}

Palavras-chave: alfabetização, pais e escola, participação de pais.

\section{Interest and difficulty of parents concerning the children's literacy}

\section{Summary}

The main object ofthis study was to analyze the data regarding the difficulties and points ofinterest in the process of teaching the children how to read and write. Twenty five mothers of children in preschool and first grade were invited in this study. A questionnaire was used to determine the interests and difficulties ofthe mothers as well as their availability in time for this matter. The results have shown that the subject ofthe study seem to be willing to participate more actively in this process at home and toghether with school. Their interests seem directed towards the evolution the writing skills and methods for teaching this children how to read and write. The difficulties which have appeared are related to conduct in the children's learning process. Key-words: literacy, parents and school, parents' participation.

\section{Introdução}

O universo familiar e suas relações no processo educacional constituem um campo pouco estudado, mas muito importante para o desenvolvimento e aprendizagem da criança. No caso da alfabetização, por exemplo, há alguns aspectos a serem considerados: o primeiro está relacionado com a criança. Pode-se entender que o fato de estar ou não preparada para a alfabetização de acordo com as condições necessárias de desenvolvimento geral é uma condição importante para o sucesso dessa aprendizagem (Schwartzman, 1992). O segundo aspecto refere-se ao contexto familiar, em suas relações com as crianças, no sentido amplo de educação e de aprendizagem (Miranda, 1992). Além da criança e do contexto familiar é importante considerar também as relações da família com a escola diante da alfabetização da criança, pois essa interação não é neutra neste contexto (Canedo, 1993; Morrow, Tracey e Maxwell, 1995).

Tais relações funcionam como forte influente neste processo. Discute-se, com certa freqüência, o grau de envolvimento e acompanhamento dos pais como fator importante na aprendizagem da criança (Guzzo, 1990; Amm e Juan, 1994; Anderson, 1995).

Teoricamente, não se contesta que a criança inicia o processo de alfabetização através de atividades da vida diária, a partir do uso de materiais escritos, juntamente com figurativos, disponíveis na casa (Castanheira, 1992). Já se efetuaram trabalhos que visavam à caracterização dos 
usos da escrita pela família como modelos ou condições de estimulação da criança, aproximando-a desses materiais. Através de investigações longitudinais feitas por diversos grupos de pesquisadores (Heath, 1982; Anderson e Teale, 1987; Wood 1987 apud Pereira e Albuquerque, 1994) verificou-se que há diferenças na relação da criança com o processo de aprendizagem, principalmente no que tange à escrita, decorrentes do ambiente no qual está inserida. Tais diferenças parecem existir, em princípio, de acordo com o contexto familiar, isto é, este determinaria em grande parte como a criança estabelece relações com diferentes objetos propícios à alfabetização, e também interferiria na natureza e qualidade de sua interação com os pais.

Estas constatações acabam não só confirmando a responsabilidade da família na aprendizagem de suas crianças, mas também ampliando o conceito de alfabetização em si, que deixa de ser domínio exclusivo da escola, para acontecer também no cotidiano do lar, no seio de relações de outra natureza que aquelas formais estabelecidas em uma instituição educacional.

Assim, ao interagir em casa nas mais diversas situações com os filhos, os pais podem oferecer objetos e condições que favoreçam a aprendizagem da criança, quando acreditam que fazem parte deste processo. O espaço que os pais identificam como contribuidor da família para o sucesso na alfabetização, seu engajamento e sua responsabilidade nesse processo determinarão em grande parte suas condutas no cotidiano com os filhos, permitindo a esses adultos a identificação de situações promissoras para a aprendizagem da leitura e da escrita da criança (Di Nucci, 1997).

Todavia, enxergar a potencialidade de diferentes ocasiões, tais como leitura de rótulos e preços de supermercado, discussões a partir de programas de TV e, naturalmente, uso de livros, revistas e outros impressos do cotidiano da criança, só acontecerá se os pais (e, eventualmente, os demais membros da família) tiverem a convicção de que tais interações são efetivamente contribuidoras para a aprendizagem da leitura e da escrita. Além disso, não basta identificar tais situações, mas perceber que a responsabilidade de promovê-las é também da família.

Atualmente, há um crescente reconhecimento nas teorias do desenvolvimento, educacional e sociológica de que escola e pais são instituições fundamentais na socialização e educação da criança. Parece que os pais estão buscando uma participação mais efetiva na aprendizagem de seus filhos, assumindo o papel de mediadores entre a bagagem familiar que a criança carrega e a realidade escolar (Grolnick e Slowiaczek, 1994).

Apesar de alguns pais mostrarem interesse na aprendizagem dos filhos, parece ser difícil assumir esse papel. É preciso refletir melhor sobre essa dificuldade e respeitar o interesse dos pais bem como suas ansiedades e angústias como educadores (Althuon, Essle e Stoeber, 1996). Segundo essas mesmas autoras, existe pouca bibliografia que trata especificamente de trabalho com pais na escola, embora seja fundamental essa interação para a aprendizagem da criança. Parece ser difícil e pouco explorada em nossa realidade a parceria entre pais e escola, o que acaba despertando nos pais mais interessados algumas curiosidades em relação à alfabetização de seus filhos e também algumas dificuldades para participar mais efetivamente desse processo.

A rigor, a parceria entre pais e escola parece ser uma via de acesso para esclarecer essas dúvidas e satisfazer essas curiosidades. De acordo com a realidade observada, a busca pela integração entre pais e escola tem caminhado bastante. Por outro lado, essa integração tem esbarrado em alguns obstáculos encontrados na diferença de concepções de alfabetização entre pais e escola. Essa diferença aparece como um dos principais obstáculos para o engajamento dos pais na alfabetização de seus filhos, o que motivou este estudo cujo objetivo foi realizar um levantamento 
de dados referentes aos interesses e às dificuldades dos pais em relação à participação na alfabetização de seus filhos e à disponibilidade de tempo em participar efetivamente desse processo.

\section{Método}

\section{Sujeitos}

O presente estudo contou com a participação de 25 sujeitos, sendo todas mães de crianças que freqüentavam a pré-escola (60\%) e $1^{\text {a }}$ série $(40 \%)$ do $1^{\circ}$ grau de um estabelecimento particular de ensino. A idade variou entre 23 e 45 anos, sendo a idade média de 29 anos. Não foram levantadas outras características de identificação por tratar-se de um estudo exploratório acerca do tema principal.

\section{Material}

Foi utilizado um questionário elaborado pela Autora cujo objetivo foi obter informações referentes a: 1) dificuldades e interesses dos sujeitos na participação da alfabetização de seus filhos; 2) disponibilidade de tempo em casa e em parceria com a escola para participar efetivamente desse processo.

\section{Procedimento}

O questionário foi entregue a todos os pais através das crianças que freqüentavam a préescola e $1^{\mathrm{a}}$ série $(\mathrm{N}=85)$. Porém, foram retomados às mãos da pesquisadora $29,5 \%$ dos questionários $(\mathrm{N}=25)$.

Os dados foram analisados segundo a técnica de Análise de Conteúdo baseada em Bardin (1978). Os argumentos foram classificados em categorias específicas e estas em categorias globais.

\section{Resultados}

Os resultados obtidos no presente estudo parecem apontar que os sujeitos demonstraram disponibilidade para se engajarem na alfabetização de seus filhos, conforme foi apresentado em 81,09\% dos argumentos ( $\mathrm{F}=30$ ) do total de 37 (trinta e sete) argumentos ( $\mathrm{gl}=2 ; \mathrm{X} 2 \mathrm{c}=5,99 \mathrm{X} 20=$ 19,97) (Tabela 1).

Tabela 1. Categorias referentes à disponibilidade dos sujeitos

\begin{tabular}{|c|c|c|c|c|c|}
\hline Categorias Específicas & $\mathbf{F}$ & $\%$ & Categorias Globais & $\mathbf{F}$ & $\%$ \\
\hline Manhã & 6 & 16,21 & \multirow[t]{4}{*}{ Participação junto à criança } & \multirow[t]{4}{*}{16} & \multirow[t]{4}{*}{43,24} \\
\hline Noite & 6 & 16,21 & & & \\
\hline Integral & 3 & 8,11 & & & \\
\hline Fim de semana & 1 & 2,71 & & & \\
\hline Manhã & 1 & 2,71 & \multirow[t]{4}{*}{ Participação junto à escola } & \multirow[t]{4}{*}{14} & \multirow[t]{4}{*}{37,85} \\
\hline Noite & 7 & 18,91 & & & \\
\hline Integral & 2 & 5,41 & & & \\
\hline Fim de semana & 4 & 10,82 & & & \\
\hline Não disponível & 7 & 18,41 & Não disponível & 7 & 18,4 \\
\hline TOTAL & 37 & 100 & TOTAL & 37 & 100 \\
\hline
\end{tabular}


Em relação à participação junto à criança $(43,24 \%$; $\mathrm{F}=16), 16,21 \%$ dos argumentos indicaram haver disponibilidade de tempo no período da manhã e 16,21\% no período da noite. A disponibilidade em período integral foi apontada em $8,11 \%$ dos argumentos ( $\mathrm{F}=3$ ) e apenas $2,71 \%(\mathrm{~F}=1)$ indicaram o fim de semana como momento para participar da alfabetização dos filhos. $A$ participação dos sujeitos junto à escola foi indicada em 32,44\% dos argumentos ( $\mathrm{F}=12)$, havendo maior disponibilidade no período noturno (18,91\%; F=7), e em seguida no fim de semana (10,82\%; $\mathrm{F}=4)$. Em $5,41 \%$ dos argumentos $(\mathrm{F}=2)$ foi identificada a disponibilidade em período integral e apenas em $2,71 \%$ dos argumentos $(\mathrm{F}=1)$ foi indicado o período da manhã. A não disponibilidade para participar da alfabetização dos filhos em casa e em parceria com a escola foi apontada em $18,41 \%$ dos argumentos $(\mathrm{F}=7)$.

Como já apontavam Guzzo (1990), Amm e Juan (1994) e Anderson (1995), o envolvimento e acompanhamento dos pais é um fator bastante contribuidor na aprendizagem da criança seja no cotidiano do lar, seja em parceria com a escola. Apesar dos obstáculos encontrados no cotidiano como por exemplo o trabalho fora de casa, pode-se considerar que há pais interessados no processo alfabetização ao que tange à disponibilidade de seu tempo para dedicação à aprendizagem de seus filhos. Isso parece indicar uma conscientização desses pais em relação ao seu papel nesse contexto e também da importância da parceria com a escola.

Na escola estudada, o método de alfabetização adotado é o sociointeracionista, sobre o qual muitos pais ainda não têm informações a respeito. Esse método difere do método tradicional através do qual, muito provavelmente, esses pais foram alfabetizados. Essa diferença de concepção de método de alfabetização parece implicar, por um lado, a falta de interesse de alguns pais em estar inseridos no processo de alfabetização dos filhos e, por outro, a necessidade de se buscar informações para enfrentar as dificuldades encontradas por eles ao acompanharem a aprendizagem de seus filhos em casa e em parceria com a escola. 
Tabela 2. Categorias referentes às dificuldades e interesses dos sujeitos

\begin{tabular}{|c|c|c|c|c|c|}
\hline Categorias Específicas & $\mathbf{F}$ & $\%$ & Categorias Globais & $\mathbf{F}$ & $\%$ \\
\hline Falta de tempo & 6 & 16,21 & \multirow[t]{4}{*}{ Participação junto à criança } & \multirow[t]{4}{*}{16} & \multirow[t]{4}{*}{43,24} \\
\hline Não conhece o método & 6 & 16,21 & & & \\
\hline Falta de didática & 3 & 8,11 & & & \\
\hline Não sabe ajudar & 1 & 2,71 & & & \\
\hline Condutas diante de erros & 1 & 2,71 & \multirow[t]{15}{*}{ Participação junto à escola } & \multirow[t]{15}{*}{14} & \multirow[t]{15}{*}{37,85} \\
\hline Organização de horários & 7 & 18,91 & & & \\
\hline Cobrança dos pais & 2 & 5,41 & & & \\
\hline \multicolumn{3}{|l|}{ Reciclagem de pais } & & & \\
\hline \multicolumn{3}{|l|}{ Obtenção de material } & & & \\
\hline \multicolumn{3}{|l|}{ Formas para motivar } & & & \\
\hline \multicolumn{3}{|l|}{ Lição de casa } & & & \\
\hline \multicolumn{3}{|l|}{ Matemática } & & & \\
\hline \multicolumn{3}{|l|}{ Leitura e escrita } & & & \\
\hline \multicolumn{3}{|l|}{ Atenção e concentração } & & & \\
\hline \multicolumn{3}{|l|}{ Evolução da escrita } & & & \\
\hline \multicolumn{3}{|l|}{ Participação genérica } & & & \\
\hline \multicolumn{3}{|l|}{ Participação efetiva } & & & \\
\hline \multicolumn{3}{|l|}{ Relação pais-escola } & & & \\
\hline Percepção de interesse & 4 & 1082 & & & \\
\hline Ausência de dificuldade & 7 & 1841 & Não disponível & 7 & 18,4 \\
\hline TOTAL & 37 & 100 & TOTAL & 37 & 100 \\
\hline
\end{tabular}

As dificuldades e os interesses dos sujeitos em relação à participação na alfabetização de seus filhos foram apontadas em 72,64\% dos argumentos $(\mathrm{F}=69)$ do total de 95 (noventa e cinco) argumentos $(\mathrm{gl}=5 ; \mathrm{X} 2 \mathrm{c}=11,07 \mathrm{X} 2 \mathrm{o}=69,30)$ (Tabela 2).

Em relação às dificuldades (38,95\%; $\mathrm{F}=37$ ) dos pais na alfabetização de seus filhos, $12,63 \%$ dos argumentos $(\mathrm{F}=12)$ indicaram que os sujeitos não sabem como ajudar as crianças na aprendizagem e 3,16\% dos argumentos $(\mathrm{F}=3)$ revelaram insegurança dos pais quanto a cobranças na aprendizagem de seus filhos. Ainda, 7,37\% dos argumentos $(\mathrm{F}=7)$ apontaram dificuldades em relação a como agir diante de erros, dúvidas e trocas das crianças e 3,16\% dos argumentos ( $F=3$ ) revelaram a dificuldade em organizar horários de estudo. Por outro lado, a falta de tempo (4,21\%; $\mathrm{F}=4)$, a falta de didática $(2,10 \% ; \mathrm{F}=2)$ e o não conhecimento do método $(6,31 \% ; \mathrm{F}=6)$ parecem contribuir para o não engajamento dos pais.

Quanto aos interesses (33,69\%; $\mathrm{F}=32)$ dos pais, parece ser importante o destaque dado por eles sobre a necessidade de reciclagem $(6,31 \% ; \mathrm{F}=6)$ e de informações sobre a evolução da escrita na criança (6,31\%; $\mathrm{F}=6)$ para se engajarem na alfabetização de seus filhos. Entre as necessidades mais emergentes para o engajamento efetivo dos pais parece estar a falta de orientação em relação a formas para motivar a criança a aprender $(5,27 \%$; $F=5)$, manter sua atenção e concentração nas atividades escolares $(3,16 \% ; \mathrm{F}=3)$ e obter material que favoreça a aprendizagem $(1,06 \% ; \mathrm{F}=1)$. Há ainda interesse em saber como agir com a lição de casa $(4,21 \%$; $\mathrm{F}=4)$, com as dificuldades na matemática $(4,21 \%$; $\mathrm{F}=4)$ e com a leitura e escrita $(3,16 \% ; \mathrm{F}=3)$.

Parece que os pais buscam uma participação mais efetiva na aprendizagem dos filhos em 
casa e junto à escola. Porém, eles necessitam de orientação mais dirigida à alfabetização da criança, por exemplo, como ajudar a criança na lição de casa ou em outras situações apontadas pelos sujeitos, pois eles percebem as etapas da aprendizagem da leitura e da escrita bem como as dificuldades encontradas por seus filhos, mas não sabem como podem auxiliar na aprendizagem de seus filhos.

A ausência de dificuldades dos pais foi apontada em 2,10\% dos argumentos ( $\mathrm{F}=2$ ), o que pode revelar uma real ausência de dificuldades em decorrência da busca de informações ou o não engajamento efetivo na alfabetização de seus filhos.

A participação dos pais na alfabetização foi apontada em 11,57\% dos argumentos ( $\mathrm{F}=11)$, sendo que as atitudes genéricas foram enfocadas em $5,26 \%$ dos argumentos $(\mathrm{F}=5)$ e as atitudes mais efetivas em casa foram apontadas em 6,31\% dos argumentos ( $F=6)$. Embora essa participação não pareça estar relacionada conjuntamente com a escola, alguns sujeitos parecem ter consciência da importância da relação pais-escola $(5,26 \% ; \mathrm{F}=5)$ na alfabetização das crianças. Alguns argumentos indicam que os sujeitos percebem $(8,43 \% ; \mathrm{F}=8)$ as dificuldades $(1,06 \% ; \mathrm{F}=1)$ e, principalmente, o interesse (7,37\%; $\mathrm{F}=7)$ das crianças na aprendizagem da leitura e escrita.

Parece que essa participação acaba refletindo um discurso teórico, principalmente quando se trata da parceria entre pais e escola, já que não foram apontadas situações e/ou atividades efetivas na prática dessa parceria. Por outro lado, foram apontados o interesse e a disponibilidade dos sujeitos para o engajamento na aprendizagem de seus filhos, o que parece revelar que os pais estão começando a caminhar para a parceria entre pais e escola na alfabetização das crianças.

\section{Conclusões}

A partir da análise dos dados obtidos no presente estudo pode-se concluir que:

1. a maioria dos pais mesmo com restrições demonstra disponibilidade para participar em casa e em parceria com a escola, para se engajar na alfabetização de seus filhos.

2. há demonstração de interesse dos pais em obter informações para participarem mais efetivamente da alfabetização de seus filhos.

3. os pais parecem estar mais conscientes da parceria com a escola.

4. os interesses dos pais parecem estar voltados, principalmente, para a organização do cotidiano para a aprendizagem da criança; para a evolução da escrita da criança; e para os métodos de alfabetização.

5. as dúvidas dos pais parecem estar relacionadas às condutas diante de erros e dúvidas das crianças; melhor forma de orientar a criança na aprendizagem, principalmente na lição de casa.

De acordo com Di Nucci (1997), a concepção de alfabetização dos pais está relacionada ao método de alfabetização, o que implica a orientação quanto à aprendizagem da criança através do método adotado pela escola bem como a participação dos pais na prática nos contextos familiar e escolar. O discurso dos pais revela uma prática superficial e pouco efetiva que pode ser conseqüência da falta de informações e do pequeno espaço aberto pelas escolas.

Parece que os resultados obtidos neste estudo revelam a necessidade de se estruturar efetivamente a relação pais-escola através de espaços ainda não conquistados que possibilitem o esclarecimento de dúvidas dos pais e a orientação dos mesmos em parceria com a escola na alfabetização das crianças. 


\section{Referências}

Althuon, B. C.; Essle, C.H.; Stoeber, I.S. (1996). Reunião de pais: sofrimento ou prazer?. São Paulo. Casa do Psicólogo.

Amm, R.; Juan, S. (1994). A parent education success story: the parents as teachers program in the US and Australia. Australian Journal of Early Childhood.19(2): 10-15.

Anderson, J. (1995). How parents' perceptions ofliteracy acquisition relate to their children' s emerging literacy knowledge. Reading Horizons. 35 (3): 209 - 228.

Bardin, L. (1978). Análise de conteúdo. Lisboa: Edições Setenta - Persona.

Cânedo, L.B. (1993). A família, a escola e a questão educacional. Leitura: Teoria e Prática. 12 (21): 3 - 9.

Castanheira, M.L. (1992). Da escrita no cotidiano à escrita escolar. Leitura: Teoria e Prática. 11 (20): 34 - 45.

Di Nucci, E.P. (1997). Participação de pais na alfabetização de filhos em pré-escola: estudo de representações. Dissertação de Mestrado. Pontifícia Universidade Católica de Campinas. SP. Brasil.

Grolnick, W.S.; Slowiaczek, M.L. (1994). Parent's envolviment in children's schooling: a multidimencional conceptualization and motivation model. Child Development. (65): 237 - 252.

Guzzo, R.S.L. (1990). A família e a educação: uma perspectiva da interação família-escola. Estudos de Psicologia. 7(1): 135 - 139.

Miranda, M.M. (1992). Os usos da escrita no cotidiano. Leitura: teoria e prática. 20: 17 - 33.

Morrow, L.M.; Tracey, D.H. e maxwell, C. M. (1995). A survey of family literacy in the United States. USA: IRA.

Pereira, T.N.C.; Albuquerque, L.N.M. (1994). Convivendo com os usos da escrita antes da escola. Série Documental - MEC. Relatos de Pesquisa. (21): 4 - 25.

Schwartzman, J.S. (1992). A criança com dificuldades na escola. Temas sobre desenvolvimento. 7: 19 - 25. 